\title{
TEACHING ANTHROPOLOGY SPECULATIVELY
}

\author{
Andrea Gaspar ${ }^{1}$ \\ University of Coimbra, Portugal
}

This article is an exploration into what a speculative pedagogy can be. Describing a series of pedagogic experiments at the University of Coimbra with undergraduate students in anthropology who engaged in playful empirical exercises based on a "what if" and ludic ways of learning (and teaching), I argue that these exercises have an eventful, speculative character in the sense that they are not meant to instruct or provide theoretical contents about what ethnography or anthropology is; neither are they meant to lead students in a process of conceptual and empirical discovery that is known in advance. Rather, they were designed to produce unpredictable effects and surprise both for those learning and those teaching.

Keywords: anthropology, speculative pedagogy, speculative research, idiotic events, performative turn, design

\section{FROM SPECULATIVE RESEARCH TO SPECULATIVE PEDAGOGY}

In the last decades there has been a turn in social sciences to the performative, which is related to a shift in the relation to the empirical: research, and research methods, are now understood as non-representational (Law 2004; Back \& Puwar 2012; Lury \& Wakeford 2012), which means that the empirical is not a given nor something out there to be mapped, collected, described and analysed; the empirical is something that is brought into being through the research process (Law 2004; Savage 2013). This performative relationship between research and the empirical recently became more proactive - it has turned speculative (Wilkie et al 2017).

1 Department of Life Sciences, Faculty of Sciences and Technology. I would like to express my gratitude to the anonymous reviewers for their insightful comments on an earlier version of this text. Special thanks also to the students with whom I developed these pedagogic exercises, whose curiosity and engagement were key to turning these exercises into playful and adventurous learning experiences. Author’s contact: gaspar.andrea@gmail.com. 
Speculation refers to a sensibility to generate the new through research, in which the difference regarding the performative is temporality. The main influence on the social scientists' engagement with speculative temporality has been the philosophy of science (mainly A. N. Whitehead, I. Stengers and G. Deleuze), but also design. Speculative Design emerged as a challenge to user-centred and corollary functionalist assumptions that constitute modern rational planning. The aim of Speculative Design is not to provide techno-aesthetic solutions to pre-defined problems or to "domesticate" technical inventions, but rather to mobilise design as a "catalyst for social dreaming" (Dunne \& Raby 2013: 189). Social sciences are borrowing this temporality for their own ways of producing knowledge whereby the empirical is understood through a different temporal lens: the empirical is something to be brought into being. The interest in the speculative, either in design or social research, is an impetus to resist the linearity of modern time (Savransky et al. 2017: 4) and the rational predictability that is associated to it, enabling us "to consider temporality as it is formed through its own patterns of becoming rather than through the imposition of a preformatted geometry"(ibid). Thus, speculative research emerges not only as a more inventive and creative mode of doing research, but mainly through the cultivation of an eventful sensibility (Michael 2012a; 2012b; 2015) or as Savransky et al. put it, a pragmatics that deals with eventful temporalities (2017: 7). In other words, the speculative is a device for opening up futures rather than predicting them or closing them down: it is learning how to work outward from the contingencies; a pragmatics that involves acting on possibilities and demands "new habits and practices of attention, invention and experimentation" (Savransky et al. 2017: 2) and "modes of relating to the not-yet" (ibid.: 5).

Notwithstanding anthropology's long tradition of epistemic estrangement and a long genealogy in the "deployment of the contradiction, the counterintuitive, the paradox, the rupture as a source of methodological revelation" (Comaroff 2010: 531) - a methodological sensibility that could fairly be considered speculative in its own right - the shape that research explicitly and proactively assumes in speculative anthropology, however, remains unexplored - despite some attempts to experiment with what speculative ethnography can be (Gaspar 2018). The relationship between speculative research and anthropological pedagogy offers interesting opportunities for that endeavour. Some of the recent literature on pedagogy in anthropology explores the relationship between pedagogy and uncertainty (Alexander 2017; Harp-Rushing 2017). These debates, however, focus primarily either on uncertainty as an outside, as part of a social context (for example, considering "how to teach and prepare students for futures defined by uncertainty," Alexander 2017: 1), either as something achieved through a critical, reflexive practice able to unsettle "knowledge, beliefs, hopes and prejudices" (ibid: 3 ) working thus as a political mode of resistance (Harp-Rushing 2017). Nevertheless, in any of these approaches uncertainty is something to be produced or even designed (through means other than critical reflexivity). ${ }^{2}$ Drawing on a set of pedagogic experiments in Coimbra, my aim is to explore this possibility.

2 Some experiences concerning the use of tools for pedagogy in anthropology worth mentioning are, for example, Suzanne Scheld's account of the use of letter writing for learning anthropology (2009), or "gaming anthropology", a sourcebook with a series of experiences that have used games for teaching anthropology (Collins et al. 2017), working also as an example of a design sensibility applied to anthropology. 


\section{ANTHROPOLOGY IN COIMBRA}

Once, while in my first year of teaching, I asked students in a course of "Material Culture and Museums" to research the biography of a person through the biography of an object, which implied doing interviews with someone about the history of a personal object belonging to that person as a means of investigating that person's life history. I imagined that students would be prompted to explore objects for the sake of knowing more about people's lives, but they actually revealed themselves to be very resistant to the idea and a great part of them just could not figure out "what I wanted": it was not clear to them if they should do biography of an object or rather of a person. "Both," I explained; "the object would be the methodological medium, the pretext for researching biographic-social worlds with the goal of understanding that objects and persons' biographies are intermingled." Still, from a practical-methodological point of view, most did not find it clear, and some of them asked for instructions on what to do - which at the time I felt as a sort of heresy! (as an anthropologist I tend to take for granted that ethnography is a tacit, learning-by-doing kind of skill about which there are no "rules" to follow). What most of the students ended up doing, which for me was very frustrating, was simply adapting the biography of a subject they had already collected for another course by adding an object to it, while literally reproducing the discourse collected. At that point I realised I had a problem: the expectations I had for students were completely mismatched to what they could do in reality. This is revelatory to some extent of the specificities of my academic institutional context but also affirms the fact that the methodological and pedagogic toolkit that I had inherited from previous generations of anthropologists was not adequate for these conditions.

The department where I am teaching is the same department where I graduated in anthropology more than fifteen years ago, although it is now barely recognizable to me. The main difference is that it used to be an Anthropology Department but some ten years ago it was transformed into a broader Life Sciences Department that includes all the biological sciences. Most of my students are, unsurprisingly, more interested in physical rather than social anthropology. While in the former Anthropology Department students would specialize in one of the areas - social anthropology or physical/biological anthropology - nowadays students acquire skills in both fields, which means that for the majority of them, social anthropology is merely burdensome. I learned that from the students' perspective, the social anthropology courses are too theoretical when compared to the biological ones. In physical anthropology they have laboratories for hands-on experiments that provide them the opportunity to collect data in the field. In social anthropology we do not have that. As practical learning, we either ask students to write essays or read texts and discuss them in class, or make presentations in class based on those readings, nonetheless all of these are theoretical exercises. The kind of empirical exercises that I once did as a student (essays that were based in small ethnographic exercises) somehow became unadjusted to students in this current academic context, not only because learning in a neoliberal academy is generally expected to be more practical (Tokumitsu 2017), but also for contextual reasons. While formerly a degree in Anthropology would take four to five years, with Bologna's higher education reform the degrees have shrunk to three years. In addition, each of us in social anthropology teach an average of three courses per semester with around 60 to 100 students per course, which makes it virtually impossible for us to guide students in an "old style" empirical process or even read all their essays. As a consequence, students do not acquire the skills to perform what we would consider proper empirical exercises, and thus, when writing essays or any other basic empirical exercises in social anthropology, what they often do is just reproduce "native" discourses, taking them for granted as "information". The problem I 
want to highlight - which is shared among my colleagues - is that we seem to try to teach social anthropology with a nostalgic, idealized model of the social-anthropology student in mind, corresponding to a pre-Bologna Accord world. Rather than complaining about the contextual and institutional conditions that brought us to this situation, I will describe how I transformed those conditions into inventive pedagogies; how very pragmatically I tried to turn the limitations into possibilities, which is something I consider related to a speculative sensibility - according to Stengers (2010), "Pragmatism is the care of the possible."

\section{DESIGNING PEDAGOGIC EXERCISES SPECULATIVELY}

Unsatisfied with my previous pedagogic attempts, I embarked on what I called "laboratories" in social anthropology. If physical anthropology has "laboratories" and these are what seduce students to that area, I wondered what laboratories of social anthropology could be like? That was how I transformed the practical lessons of two courses in two laboratories: one, a Laboratory in Visual Anthropology and the second, a Laboratory in Material Culture and Museums. These laboratories consisted of a set of exercises developed during each practical lesson (these courses are divided into thirteen lectures; the class is also divided in smaller groups with twelve practical lessons for each group, all with two hours for each lesson). We usually met in the classroom, where I would give instructions to students on a series of activities meant to collect empirical material, and 30 minutes before the end of the lesson they were to return to class to discuss the material collected. First I will describe briefly these exercises before discussing how they turned into what I consider eventful pedagogies.

\section{Laboratory in visual anthropology}

\section{Module 1: Observational Photography: exploring the work of one photographer}

I used the first three lessons of this laboratory to introduce students to an observational sensibility asking them to explore the work of one photographer (not necessarily an anthropologist) whose work has an observational character. I gave students a list of photographers, ${ }^{3}$ from which they could choose and explore the work of one and make a presentation about it in class. ${ }^{4}$ This initial set of classes, consisted in students' presentations and my comments on them. Their presentations provided me opportunities to highlight some aspects that are particularly important to ethnographic observation. For example, the attention to the specific, the relationality and intimacy created with the subjects photographed, the tension between the subjective and the 'realistic' objective, etc. In the following three lessons, students would experiment with the use of visual media for empirical observation.

3 Henri Cartier-Bresson, Robert Frank, Diane Arbus, Robert Doisneau, Walker Evans, Robert Capa, Jeff Wall, Thomas Struth, Wolfgang Tillmans, Elliott Erwitt, Stephen Shore, William Eggleston, Martin Parr and Nan Goldin.

4 Initially the intention was that students could choose to explore either a photographer or a filmmaker, or a designer, since one of the theoretical topics of the course is anthropology through design, however those options did not have many followers as all the students ended up doing their exercises on photographers only. 


\section{Module 2: Practicing with visual media on the campus}

The first of this second set of lessons started with students doing observation outside the classroom on the campus. They would choose a place where they would remain for about an hour and they would write fieldnotes on what they could observe. Then they would come back to class for a half an hour discussion based on the material gathered. These were opportunities for me to teach them how to take fieldnotes and what these fieldnotes should look like, stressing for example the importance of gathering detail from which we can afterwards interpret.

In the next lesson they did the same observational exercise but using photography with mobile phones to document their observations. While in this first approach photography was used in a non-interactive way, a week later the exercise turned into an interactive one: students were told to interact with people on the street, trying to discover who they were and what they were doing in Coimbra, and ask permission to take pictures of them with the aim of documenting the interaction. In the next lesson students showed their visual materials and we discussed them. One of the issues discussed was the difficulties in receiving permission and the problems and possibilities that the medium creates. For instance, some of the people the students interacted with did not give permission to be photographed, while others were happy to take selfies therefore controlling their own representation of themselves.

\section{Module 3: Documenting «Baixa» for producing a visual essay}

The final set of exercises, composed of three other lessons, was in Baixa (downtown Coimbra), where they would be using the visual media they had been experimenting with previously to collect material for a visual essay about this place. Baixa is a socially depressed area of the city, experiencing decay and abandonment, alongside the threat of speculation and gentrification. The intention was to introduce students to "Há Baixa", ${ }^{5}$ a collective of architecture students from the University of Coimbra aiming to intervene in the public space through architectural infrastructures and social and cultural activities. These exercises were envisioned as an opportunity to provide anthropology students a contact with this project so that in the future they could explore ways of collaboratively contributing to it through anthropology. ${ }^{6}$ To some extent, and in tune with a current debate in anthropology (Estalella and Criado: 2018), this was a way of exposing them to the challenges of (ethnographic) intervention and collaboration.

The exercise in Baixa started with a walk, where I asked students to follow me silently, while paying attention to as much sensorial information as they could get in order to "read" the place. After one hour walking, we sat on the street and I asked students to write fieldnotes of what they observed, based on their memory and physical sensations of the place. This was a precious opportunity for me to intervene in their perception of what an anthropologist is expected to collect as data. In this situation, students tended to produce general impressions rather than capturing specific details, and only a minority of them were able to describe detail, for example parts of conversations they heard, images they captured, etc.

5 https://www.facebook.com/habaixa/

6 There had been a previous participation in this project of a group of students of our Master's course in social and cultural anthropology under my supervision with another colleague from the department. The participation of these students had been quite explorative in searching how to collaborate with architects, though they struggled to figure that out in such a short time. Starting this contact with the undergraduates occurred to me as a way to integrate students earlier in this project for exploring future collaborations. 
Then, in the next lesson, in the first half of the lesson we had a conversation with one of the architecture students of "Há Baixa" who presented the project to us and opened a discussion about the problems of Baixa. In the second half of the lesson students experimented with ethnographic drawing: the instructions were that they should choose a place where they would draw what they observed from that place, during 45 minutes. Drawing what they observed did not necessarily mean drawing what they saw. I stressed that drawing, in this case, was not meant as a product but rather as a part of the process of observation and therefore they did not need to limit themselves to what they saw. What they would register would be all the things they would select to register visually from what they observed during a certain time. I gave them some examples and showed them pictures of my participation in a similar exercise, a workshop proposing to explore anthropology through drawing in the EASA conference in Milan, 2016. Unsurprisingly, a great part of students in fact limited themselves to drawing what they saw as an objective register. Some of them spent most of their time choosing the place, although I insisted that it could be any place, but they were too focused on the object to be drawn rather than on the observational process. Some of them, however, did very interesting drawings with a level of detail that I would consider very observational (see picture 1) - again, this situation opened up the opportunity to explain to them what is considered observational and what is not, and why.

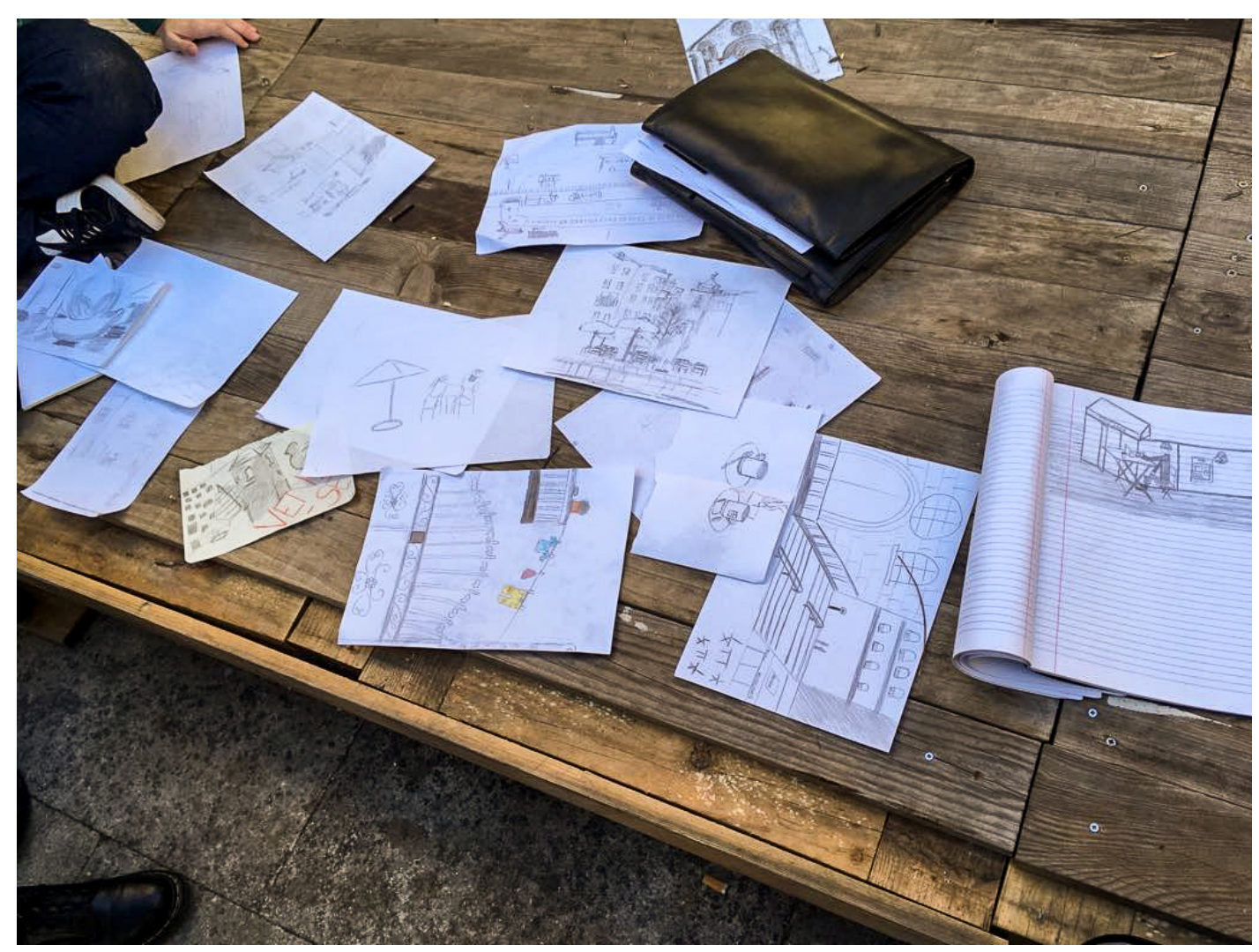

Picture 1: Observational drawings made by the students. Picture taken by the author.

The next exercise (the 3rd lesson in Baixa) consisted of a 30 minute walk that students would perform individually, while also taking observational pictures with mobile phones. During this walk they were supposed to choose a place where they would remain for another 45 minutes and observe the place - I suggested they choose cafés and tascas (small restaurants or places for snacks and drinks usually attended by local people). The challenge now was to inter- 
act with people in those places while registering as much observational material as they could, through fieldnotes, drawings or pictures. I distributed these instructions to students on small pieces of paper that they carried along with them and I emphasized the need to be observational in a specific place. Most of the students, however, went directly in search of opportunities for interviews, since the instructions mentioned "interaction" with people. Hardly any of them really stayed in the same place for 45 minutes as I had suggested, nor did they collect material from observation other than what people said to them - they approached people on the streets and shops asking them, for example, what they thought of Baixa, what it means to them and how Baixa has changed over time factually. Even though I tried to emphasize the importance of their own perception and their embodied experience, while presenting their visual essays later in the course most of the students tended to depict Baixa as an objectified whole. Some of them even tried to refer to the senses in general - "In Baixa we usually hear this and that, and the smells are these and that" - but without showing an understanding of what a situated and embodied sensorial account could be. Although students have lectures in which the partial and interpretational character of ethnographic knowledge is emphasized, what this exercise revealed is that they tend to think of ethnography as a representational exercise. These exercises were valuable not only because they provided me the possibility to intervene in this and many other perceptions, but also because they provided the conditions for the occurrence of epistemic events that are potentially transformative of what is taken for granted not only by students but for all of those involved (teacher included). In one of those moments when I was confronting students with what they did wrong, something unexpected happened, turning the pedagogic situation into an event, where I turned into an idiotic teacher (Farías and Criado 2018). I will discuss this event later on, but first I will explain the other exercises I developed simultaneously, with the same students in another course.

\section{Laboratory in Material Culture and Museums}

In Material Culture and Museums, students started with empirical exercises departing from objects. I started the course with the presentation of the plan - saying it was meant to be a laboratory where they would develop a number of practical, empirical exercises around objects in the first stage, while in the second stage they would collect objects for a small exhibitive exercise. Although I designed a plan, the plan still needed a fine-tuned definition, for example I did not have a clear idea from the outset of exactly what the activities would be for the collection of objects (which objects? How would students collect them? How would the exhibition be, and on what topic?) These were the details I kept open for refining through the course while doing it - in a certain way, I was prototyping (Corsín Jiménez, Estalella and Zoohaus 2013) my pedagogic toolkit.

\section{Module 1: Objects}

Similar to the Laboratory of Visual Anthropology, the first set of exercises consisted of going outside to observe the social life of the university campus from a material culture perspective. The theoretical topic I was approaching in the lectures of the course was Reynolds' concept of material systems, and in articulation with that, the instruction was: students should choose one object - either personal or from the environment - and observe what happens around or through it, taking observational notes of it. Some of the students focused on things from the environment - such as ATM machines, stairs or tourist buses - and looked at the social life that 
happened around it in the period they observed it. Others, however, looked at personal items, such as mobile phones, and described the behaviour of people with them. I stressed to them that the first situation turned out to be more interesting because objects were the means that opened them up to observational situations while in the second case, objects were closed in themselves, as objects to be described.

In a second lesson, they should interview people about the stories of some personal items, such as bags or pastas (the academic black leather folders that students use specifically in Coimbra as part of their traje (the traditional academic outfit). Some of them collected very interesting observational material from those who populate the space, either from students or from tourists. The topic was related to the theoretical lessons' topic, which was Appadurai and Kopytoff's "social life of things" and thus the aim was to show them that while trying to do a biography of things we are also studying the biography of people.

In a third lesson, the theoretical topic was the anthropology of consumption based on Daniel Miller's work. I started the lesson asking them to talk of something that they bought recently, why they bought it and what for. After this exercise, I told them to go outside and make the same inquiry to people and then come back to report the material they had gathered. The idea was to show them that consumption practices are related to processes of construction of identities - personal, but also collective, such as, for example class and/or culture. Finally, the fourth of these lessons was for describing Latourian networks and material agencies.

Despite certain degrees of improvisation and iteration, until this point there was nothing pedagogically speculative to mention: the exercises were means of relating to the contents that were being discussed in lectures; they were ways of eliciting some of the concepts that were already part of the courses' programme. However, it was this (albeit to some extent very conventional) practical structure (the sequence of exercises and its instructions) that nonetheless provided the speculative opportunities that I am interested to discuss here and which emerged mostly in the next exercises.

\section{Module 2: Museums}

After these initial sets of exercises around objects, we turned to the topic of museums, which started with a museum visit to the ethnographic collections of the university. At this point, I had to find out what to do in the following lessons: my problem was how to occupy a certain number of lessons with an activity that I had roughly defined as "object collection". The following idea solved my problem.

\section{"Kit of idiotic objects for social research"}

This sequence of exercises was something that was not planned in advance, although roughly planned for object collection. I imagined a device specifically for that task: a "kit of idiotic objects for social research" meant to be used as tools for opening up ethnographic conversations. I presented students a kit that I had assembled myself, but before showing it to them I explained what the "idiot" is, as a theoretical figure, ${ }^{7}$ and where it comes from and why

7 The idiot is a conceptual persona that Isabelle Stengers (2005: 995) borrows from Deleuze \& Guattari (1994: 62). The idiot, according to Stengers, "is the one who always slows others down, who resists the consensual 
is it relevant for us here. "Until now, we have been approaching objects as something which has meaning, or several layers of meanings (biographies), which the ethnographer is supposed to interpret. What about objects that do not possess any meaning?" The idiot is what does not make sense, does not have any meaning, but can open up other meanings or processes of meaning-making.

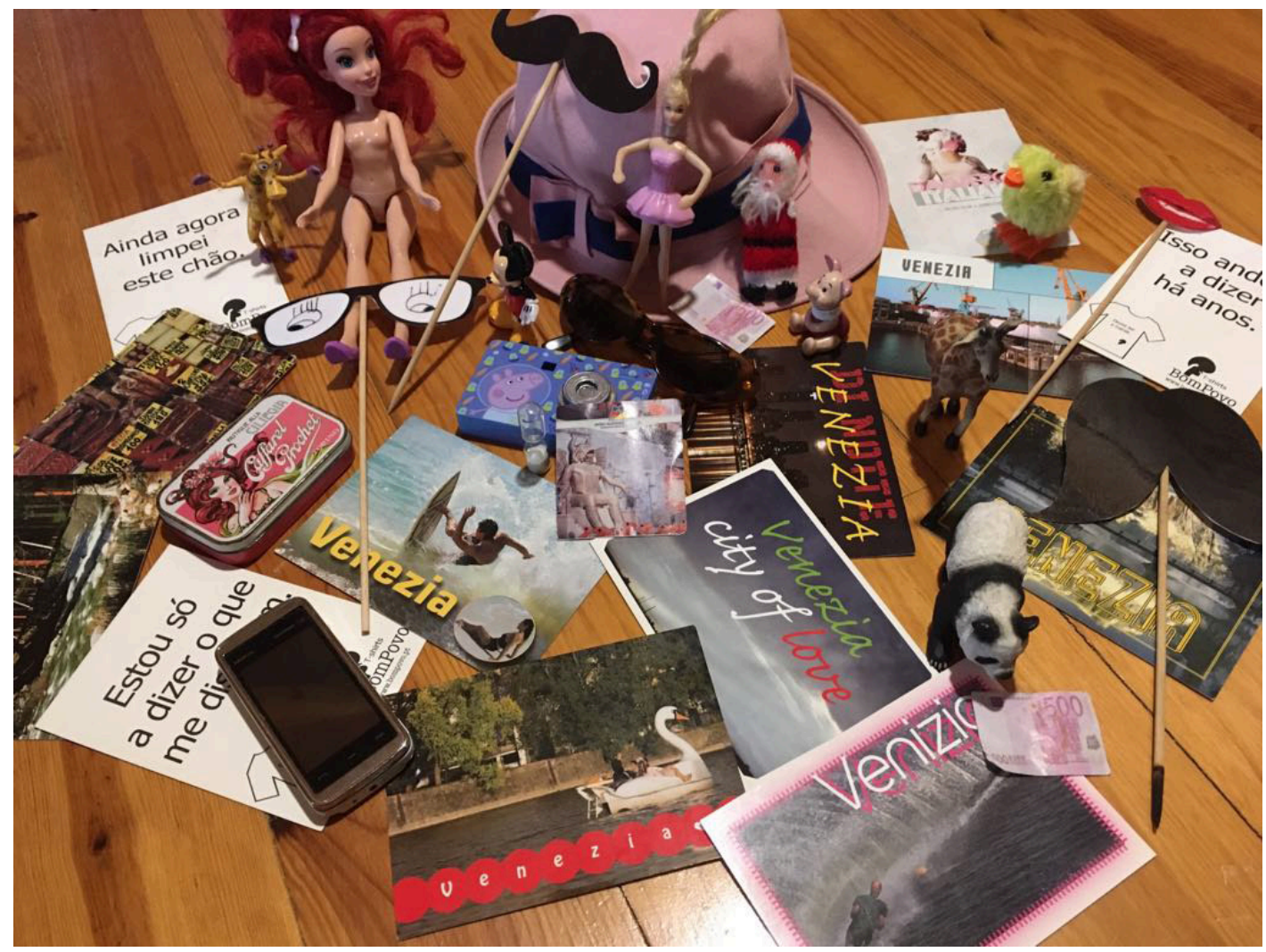

Picture 2: Objects of my own "kit of idiotic objects for social research". Picture taken by the author.

As an example of an idiotic effect, I presented myself with one of the objects I took from my kit - an apron with an image of the body of a woman in lingerie. I put the apron on to show them that presenting myself to a class that way is inappropriate, so it created a disruption in the normal course of things leading us to think of what are the appropriate ways of presenting ourselves in a classroom situation - "there are certain types of clothes we usually don't bring to a class, such as pyjamas or beach clothes, which leads us to the implicit rules of behaviour that are considered normal to a class and that we usually don't think about but perform accordingly," I told them. "This is the effect of the idiot: bringing some sort of disruption and therefore making us think about that implicit normality". In which ways can we provoke that effect, what tools do we need? In design this is almost a routine practice of extracting novelty through the intended provocation of surprise and unexpected effects that are useful for the design research process - for example, Mike Michael's (2012a 2012b) account of speculative designers' use of "cultural probes" (material devices aimed to stimulate empirical and creative effects). However, such a practice is not so common in Anthropology, although some interesting experiments are worth mentioning - for example the art-inspired anthropological modes of

way in which the situation is presented and in which emergencies mobilize thought or action" (Stengers, 2005: 994) 
research explored by Ethnographic Terminalia in the US, ${ }^{8}$ or the work of EBANOCollective in Portugal. ${ }^{9}$ The recent turn to design in anthropology also goes in that direction: for example, Design Anthropology (Gunn et al. 2013) which advocates "a distinct style of knowing" through the collaborations between design and anthropology, and Keith Murphy's work (2016), whose stance is that design should inspire newer forms of undertaking anthropology, namely through more interventionist modes of research. Objects and material culture are an opportunity for anthropology to experiment with art and design modes of intervention. It was in this spirit that I presented to the students a kit of "idiotic objects" - ranging from some of my children's toys, to unusual postcards and other intriguing but meaningless objects - and invited them to speculate about these objects' stories and meanings (see picture 2).

I distributed some of these objects to them and invited them to work in pairs, inventing a story around them, which they should perform to the class afterwards (see picture 3). Students revealed themselves as very imaginative and actually used the objects while performing the stories they themselves have made up.

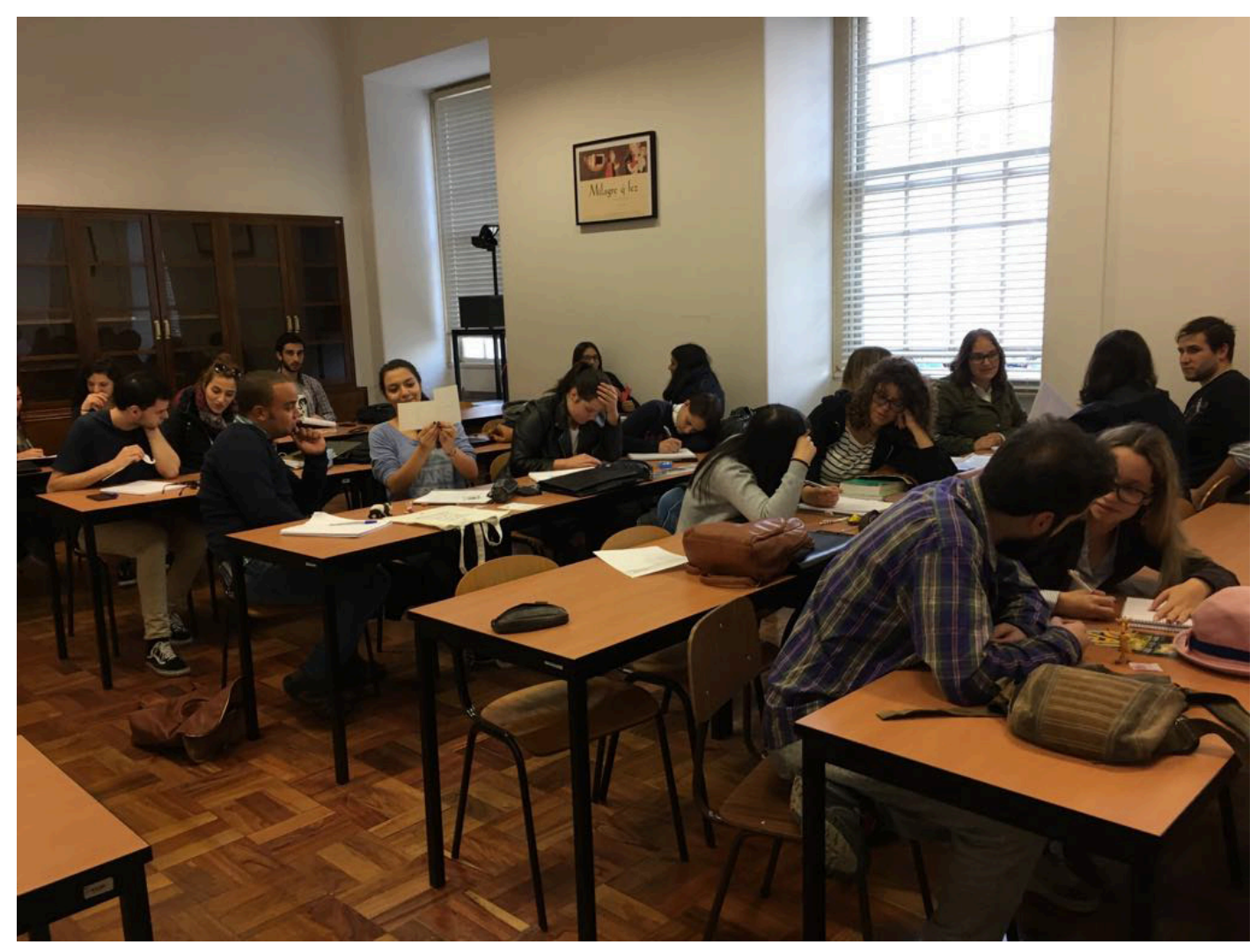

Picture 3: Students involved in their speculative exercise around "idiotic" objects. Picture taken by the author.

The following step was asking them to assemble their own "kits of idiotic objects", individually, and bring them to the class next lesson. These were the objects they would use onwards for collecting materials, which in turn would be used for our small exhibition at the end of the semester.

8 http://ethnographicterminalia.org/

9 https://www.ebanocollective.org/ 
Students collected around ten idiotic objects each and used those objects to approach people on the same basis that I did to them in class. They would invite people on the street to speculate about those objects, but with an additional ingredient: those stories would be about Coimbra. They collected a number of stories and shared them at the end of the class - some of them quite creative, some futuristic, others set in the past. Then, in another lesson, I asked them to use each of the objects individually to ask people to speculate about each object's origin and stories, again having Coimbra in them.

The aim of this exercise was to collect a certain number of objects and their stories for our small exhibition exercise. We started thinking about the concept and the pragmatics of the exhibition: what would the shape of the exhibition be, and where and how would it be presented? What would we do with the speculative stories around objects: would they be presented through a portfolio, or through little paper books made by the students? As I explained to them, we were prototyping what a speculative museum can be - prototyping is also a theoretical topic of the course (Corsín Jiménez et al 2013); an important gesture, I told them, because in anthropology objects are usually approached for what they mean, but their meaning is already closed down and made by others rather than something to be brought into being. I should stress, however, that this justification was not the primary reason I thought about this exercise as such: I did it for very pragmatic reasons: the plan I had designed for the exercise consisted of collecting a number of objects for a small exhibition. However, this raised a practical problem: if the objects to be collected were objects in the traditional material-cultural sense, that is, objectswith-meanings, with stories, objects of the people we interact with during fieldwork, then how would we deal with the problem that these are usually personal objects that people would not be willing to lend for the exhibition? Either personal objects or objects that have some sort of utility for the people who own them might be a problem for our exhibition, and so I had to find a way of using other kinds of objects and objects that students could bring seemed to be the solution. From this practical need, the articulation with the idiot and the speculative was a very short step away. This practical problem is not an irrelevant detail. My point is precisely that it was these practical problems that stimulated me toward creative articulations that otherwise would not have happened - and this in itself is a speculative gesture able to extract potential from the concrete conditions of the present.

\section{WHAT MAKES THESE EXERCISES SPECULATIVE?}

According to Diprose (2017), the way teaching is currently managed and evaluated in universities does not "foster the opening of paths for thinking," because teaching is understood in terms of Socratic maieutics and mimetic inspiration (2017: 47). Socratic maieutics is closed, predictable knowledge while inspiration, which is central to speculative thinking, is being exposed to or affected by the other: "Inspiration by the other disrupts the status quo and leads to transformations in meaning and in the reality of experience" (ibid: 47). The exercises that I am describing worked as inspiration to my own process of learning how to teach anthropology in this particular milieu. They were speculative, on the one hand, because of the way they related to theory - they were a way of opening up theoretical threads by engaging students in empirical situations. For example, considering the Baixa exercises, Design Anthropology and the collaborations between Anthropology and Design are some of the topics of the course, but the exercises, rather than just illustrating these topics, provide an opening into them, a practical 
means to explore these topics. The same is true for the idiot and the interest in intervention and the speculative as a topic: these topics are not ends in themselves but they provide openings to articulations that could not have been predicted beforehand (see the next topic). They were speculative, on the other hand, because in this process I operated somehow as a designer: in search of solutions for specific problems, I was designing exercises (planning them, adjusting them, prototyping them), and I was designing them speculatively - not just because the plans were open and I had to rely on a considerable amount of improvisation, but because I was creating the conditions for these openings. In other words, these exercises were speculative not just because I was exposing students to the other, but because the other (that which was unknown to me in first place) was being produced through the very pedagogical opportunities created. Let me now turn to examples of this.

\section{THE IDIOT AS A SPECULATIVE FIGURE: THE EMERGENCE OF THE IDIOT IN «BAIXA»}

[...] when there is thinking together, it is always of the order of the event. But the care of the event, meaning that from which the situation can receive this power - which is not usual, which is not given - this requires a whole culture of artifice... (Stengers 2011: 17).

In the Laboratory of Visual Anthropology some of the more inspiring events emerged spontaneously - though not accidentally. While we were doing the visual ethnographic exercises two interesting events occurred that are concerned with what I consider an idiotic effect (see Michael 2012a; 2012b). In one of the lectures I had invited João Peralta, spokesperson of "Há Baixa", to present the project to my students and to discuss with them the experience. João chose to meet with the students for this conversation in a wooden platform on the street (a sort of stage), in Largo do Romal, that they had constructed during the project. João's choice for this place was an act of reflexivity: he wanted to address some of the problems and contradictions of "Há Baixa". The structure had not only been imagined and constructed by the architecture students, working as an exercise of architectural auto-construction ${ }^{10}$ (Corsín Jiménez 2017), but also served as a stage for various events concerned with social architecture and urbanism during the "Há Baixa" intervention phase. ${ }^{11}$ Although it was originally meant as a temporary structure for the project, the students decided to keep it with the expectation that local residents would appropriate it for their own activities. That was not how it ended up being used. By the time we were having these lessons, the structure had been appropriated by drug users and dealers, who seemed to prefer it to the other places in downtown where they used to meet before. The wooden platform had not only been adapted (for example, a mattress was added) and appropriated by these new users, but it had also been physically vandalized. These were the people that did not count as users of the space. I do not mean that these drug users were excluded and socially marginal a-priori: what I mean is that they were marginalized by our very own process of researching and teaching what Baixa is. This event, however, potentially reopened

10 Auto-construction could roughly be defined as a method of architectural experimentation usually used by grassroots guerilla architects.

11 One of these events, organized by myself and a colleague anthropologist from my department, was a talk on open-source urbanism by Adolfo Estalella, on the 12th of July 2017. 
for us what counts as "social" in anthropology, just as much as in architecture. The situation brought together an anthropology teacher and her students trying to visually research Baixa as a social space, and architecture students trying to learn how to do architecture differently: an architecture that wants to depart from below and from the "social". But what counts as "social" for us? Architects and anthropologists together seem to take for granted certain versions of the "social". For the students of architecture, the "social" of Baixa and the people their architectural projects address are local residents and elderly people, exposing an implicit, imagined and idealized notion of "community" that excludes other people like drug addicts, prostitutes, or simply mentally disturbed people who very often wander around in Baixa. For example, one of the projects that the "Há Baixa" people mention as successful is the tote bag project. The students had invited a social design studio from Lisbon ("A avó veio trabalhar"12) to develop a project in situ with the elderly ladies who live in Baixa who suffer loneliness and abandonment. The studio imagined an activity where these ladies were put to work crafting something in which they are often very skilled, which is embroidering, thereby producing totes with a graphic layout in common - the "Há Baixa" logo. These totes were sold locally in the traditional shops of Baixa and the money was given to them. This may be an interesting example of a successful social project promoted by "Há Baixa", however, it is also revelatory of a certain kind of "social" - the traditional residents, the elderly people, precisely in a time when those residents are becoming fewer than ever (Baixa has been losing residents and transforming itself in a touristic city centre). I in turn, was struggling with the fact that anthropology students tend to reduce ethnographic observation to the making of interviews, and the interviews they did were mostly with older people, local residents or the owners of the more traditional shops because this is what counts in their imagination as the proper "social" of Baixa: very few students engaged with drug consumers and dealers, or any other people outside of these stereotypes (some of the exceptions were one student who did the exercise with gypsies and another one who observed dealers and drug buyers doing their business). Thus, there is also a tendency to find idealized versions of the social in anthropology. But while we were in Baixa, the social that did not count as social irrupted many times, offering us the opportunity to re-open what the social is: one of these opportunities was when we were talking with João about "Há Baixa" with the drug addicts behind us, looking at us, and at times disturbing us by talking louder than us, making it impossible to have a lesson on the street. This "other" social was a presence that disrupted what we were busy doing. They were curious about us, and when the time came for students to go around and do their exercise of ethnographic drawing, they approached some of the students, asking who they were and what we were doing there. ${ }^{13}$

Another idiotic disruption emerged in one of these lessons. Usually at the end of each of these lessons on the street, students would come back to discuss the material they had collected and our meeting point was on the stairs in Praça do Comércio, facing S. Bartolomeu church. In one of those occasions there was a very drunk man who stubbornly tried to interrupt our lesson; we could barely understand what he was saying but apparently he was curious about us and wanted to know what we were doing. I kept trying to ignore what felt to me like an annoying disturbance, including inconvenient obscene comments. Someone told him it was a lesson of anthropology and he asked us what anthropology was. By that time he had taken over the class,

12 Literally it means "Grandmother came to work". https://www.facebook.com/AAvoVeioTrabalhar/

13 This does not mean that these drug addicts are excluded from the people of the project "Há Baixa", quite the contrary, the collective seems to have good relationships with them. Before participating in our lesson João Peralta greeted them and chatted with them for a while before the lesson begun. However, these drug addicts were not the users they expected for this particular place. 
who were engaged in a conversation with him trying to know his life history, which was apparently very rich. This is an example of an idiotic event: an outsider, a resisting other - in this case, the social that does not count as social in anthropology - a social that is not understandable, one who it is not even possible to argue with (and therefore to consider an informant) but nevertheless a social that exists and keeps interrupting, imposing its material existence on what we are busy doing, inviting us to reflect precisely on those things that we take for granted while doing what we are doing. The power of the idiot (in this case, this situation) is precisely to open up what we routinely do and to generate the possibility to do it differently. This is an example not only of the exposure of students to the other but of generating the other within pedagogic practices: the idiot is what happened from a pedagogic situation designed as unpredictable interaction, something I could not predict beforehand in a Socratic, maieutic style, but nonetheless something that I had to care for and created the conditions for it to occur through my pedagogic practices - something that I had to design, in a speculative design sense (Dunne \& Raby 2013) - imagining a sequence of exercises, their rhythms, their sets of instructions and the specific spaces needed for them. The idiot, as a speculative event, resists the traditional Socratic maieutics exercise: although I used these events as examples to draw students' attention to the need to be open to what they find - that being observational and descriptive is all based on that - the idiot as a pedagogic event is open-ended, potentially transforming what the participants (both teacher and learners) know.

Although the idiot cannot be predicted beforehand, it is not just accidental. Cultivating the coming into being of novel and unexpected events should not be seen as just another form of conceptualism; it is a (context-dependent) pragmatics. It involves working with the limits of the possible (in my case, from a very specific institutional context and its limitations with even very pragmatic and mundane problems to solve) in order to open up the real to other possibilities, which in my case was to experiment with what a speculative, idiotic pedagogy in anthropology may be. Cultivating the emergence of the new is an artifice. Or even, I would say, a (very special) mode of design.

\section{CONCLUSION: DESIGNING FOR SPECULATIVE PEDAGOGY}

What I have described is an experiment with what could be speculative pedagogy in anthropology, a pedagogy that generates events - a pedagogy through design, to some extent. Events open up new possibilities, and my stance is that we need to learn how to cultivate eventful pedagogies. While determinism in pedagogy might encompass those situations when one conducts the teaching activities with a pre-determined path in mind (in the sense that we may already know where students would arrive), teaching speculatively, on the other hand, requires a different sensibility to the times and forms of the cognitive learning process. The learning process might rather be understood as event, able to turn those who teach into what Farías and Criado (2018) call idiotic teachers. This, I consider, is "to be lured by the possibility of futures that are more than a mere extension of the present" (Savransky et al. 2017:2), that is, the possibility that an unfavourable institutional environment for social anthropology in this particular case can turn into a laboratory for exploring how to renovate ways of learning anthropology. Transforming what is into what could be is a political gesture whereby determinism is transformed into hope (Estalella 2011). What I describe is something that we may consider belonging to the politics of the interstice (Stengers 2011: 27): something that escapes the dualism 
between power vs. resistance through which political change is usually approached, and may be key to the craft of alternative pedagogic futures. Speculating, we are reminded, "demands the active taking of risks that enable an exploration of the plurality of the present, one that provides resources for resistance, one out of which unexpected events may erupt, and alternative futures may be created" (Savransky et al.: 8).

It is worth mentioning, however, that speculation in a speculative design sense is not just being sensitive to events: it is rather an effect produced through a designed object (Dunne \& Raby 2013), or through artefacts, such as prototypes, or kits of objects such as probes that are designed to produced events (Michael 2012a, 2012b). Speculation, in that sense, is something proactive because it is carefully designed. If seen from that perspective, my pedagogic experiments open the following questions: how to design for speculative pedagogy? What are the means, the forms, the techniques, the artifices, the methods that can be deployed to produce pedagogic events? I believe that the situations (all the sequences of exercises) and material devices (for example, imagining a kit for speculative research and putting it into practice) that I described here - although only half-planned these may have been - illustrate how specific speculative pedagogic opportunities were designed for certain effects. If design (in its classic definition) is a problem-solving activity, so were the pedagogic exercises that I described, which emerged as very pragmatic solutions to very specific, contextual problems. Nevertheless, much more research should be carried out to explore the pedagogic potential of anthropology through design in order to investigate what are the forms of a speculative pedagogy. If what we are now experiencing in the discipline, with its recent performative turn, is a move away from a critical anthropology to a pragmatic one, then research remains to be done into more pragmatic ways of teaching anthropology which, I hope I have made clear with this article, is not simply reduced to more practical, hands-on pedagogies.

\section{REFERENCES}

Alexander, Patrick. 2017. "Introduction: Teaching Anthropology in Uncertain Times". Teaching Anthropology, 7(1): 1-3.

Back, Les and Nirmal Puwar. 2012. Live Methods. Oxford: Wiley-Blackwell.

Collins, Gerard Samuel, et al. 2017. Gaming anthropology: a sourcebook from \#anthropologycon. Available from https://anthropologyconorg.files.wordpress.com/2017/12/gaming-anthropology.pdf

Comaroff, John. 2010. "The end of Anthropology, Again: On the Future of an In/Discipline”. American Anthropologist, 112(4): 524-538.

Corsín Jiménez, Alberto, Adolfo Estalella and Zoohaus. 2013. "The interior design of (free) knowledge", Journal of Cultural Economy, 7:4.

Corsín Jiménez, Alberto. 2017. "Auto-Construction Redux: The City as Method."Cultural Antbropology32(3): 450-478.

Deleuze, Gilles and Felix Guattari. (1994). What is philosophy? London; New York, NY: Verso.

Diprose, Rosalyn. 2017. "Speculative research, temporality and politics".Pp. 39-51in Speculative Research: the lure of possible futures, edited by Alex Wilkie et al. London and New York: Routledge.

Dunne, Anthony and Fionna Raby. 2013. Speculative Everything: Design, Fiction and Social Dreaming. Cambridge, MA and London: MIT Press. 
Estalella, Adolfo and Tomás S. Criado (eds). Experimental Collaborations: Ethnography through fieldwork devices. Oxford and New York: Berghahn.

Estalella, Adolfo. 2011. Ensamblajes de esperanza: un estudio antropológico del bloguear apasionado. $\mathrm{PhD}$ thesis. Universitat Oberta de Catalunya.

Farías, Ignácio and Tomás S. Criado. 2018. "Co-laborations, entrapments, intraventions: Pedagogical approaches to technical democracy in architectural design", in "Re-learning Design: Pedagogical Experiments with STS in Design Studio Courses”,Diseña, 12:228255.

Gaspar, Andrea. 2018. "Idiotic encounters: experimenting with collaborations between ethnography and design." Pp. 94-113 in Experimental Collaborations: Ethnography through fieldwork devices, edited by A. Estalella and T. S. Criado. Oxford and New York: Berghahn.

Gunn, Wendy, Ton Otto and Rachel Charlotte Smith. 2013. Design Anthropology: Theory and Practice. London and New York: Bloomsbury Academic.

Harp-Rushing, Kyle. 2017. “Teaching Uncertainty: An Introduction.” Teaching Tools, Cultural Anthropology website, Retrieved February 28, 2017 (https://culanth.org/fieldsights/1077teaching-uncertainty-an-introduction).

Law, John. 2004. After Method: Mess in social science research. London and New York: Routledge. Lury, Celia and Wakeford, Nina. 2012. Inventive Methods: The happening of the social. London and New York: Routledge.

Michael, Mike. 2012a. 'De-signing the Object of Sociology: Toward an “Idiotic”Methodology'. The Sociological Review 60(S1): 166-83.

—. 2012b. “What Are We Busy Doing?”: Engaging the Idiot'. Science, Technology, \& Human Values 37(5): 528-54.

Murphy, Keith. 2016. "Design and Anthropology". Annual Review of Anthropology45: 433-49.

Savage, Mike. 2013. The 'social life of methods': A critical introduction. Theory, Culture $\xi^{\circ}$ Society 30 (4), 3-21.

Savransky, Martin et al. 2017. "The lure of possible futures: on speculative research". Pp. 1-17 in Speculative Research: the lure of possible futures. Edited by Alex Wilkie et al. London and New York: Routledge,.

Scheld, Suzanne. 2009. "Letter writing and learning in anthropology". The Journal of Effective Teaching 9:3, 59-69.

Stengers, Isabelle. 2010. "The care of the possible". Interview by E. Bordeleau. (K. Ladd, Trans.). SCAPEGOAT: Architecture | Landscape | Political Economy01: 12-17, 27.

—. 2005. "The cosmopolitical proposal". Pp. 994-1003 in Making things public, edited by B. Latour and P. Weibel. Cambridge, MA: MIT Press.

Tokumitsu, Miya. 2017. "In defense of the lecture". Retrieved February 28, 2018 (https://jacobinmag.com/2017/02/lectures-learning-school-academia-universitiespedagogy?platform=hootsuite)

Wilkie, Alex, et al. (eds.) 2017. Speculative Research: The lure of possible futures. London and New York: Routledge. 